[Radiocarbon, Vol 25, No. 2, 1983, P 711-718]

\title{
CURREINT ${ }^{14} \mathrm{C}$ MEASUREMENTS WITH THE UINIVERSITY OF WASHINGTON FN TANDEM ACCELERATOR
}

G W FARWELL, P M GROOTES, D D LEACH, F H SCHMIDT AND MINZE STUIVER

Nuclear Physics Laboratory and Quaternary Isotope Laboratory University of Washington, Seattle, Washington 98195

ABSTRACT. Our accelerator mass spectrometry (AMS) system shows a one-to-one relationship between sample ${ }^{14} \mathrm{C}$ concentrations determined by AMS - and by $\beta$-counting. Measurements of unknown samples against a standard indicate that ${ }^{14} \mathrm{C}$ concentration measurements to better than $2 \%$ can be made. For a 30 -second data collection interval in a typical run of 100 intervals, the variability of the beam injected into the accelerator is ca $2 \%$, that of the machine transmission is ca $4 \%$, and counting statistics give $4.7 \%$ standard deviation for a sample of $80 \%$ of modern carbon.

\section{INTRODUCTION}

The University of Washington accelerator mass spectrometry (AMS) system, which uses an FN tandem Van de Graaff accelerator, has been described in Farwell et al (1980) and Farwell, Schmidt, and Grootes (1981). Technological advances in this system during the past year, including enhancement and stabilization of the overall ion transmission, are reported in Farwell et al (1983) .

To minimize the influence of isotopic fractionation in ion source and accelerator, measurements are made by switching back and forth between the sample to be measured and a standard sample. For each sample, the number of $14 \mathrm{C}^{+4}$ ions detected in a 30-second counting period is compared with the accompanying ${ }^{12} \mathrm{C}^{-}$beam current collected simultaneously in a side Faraday cup located downstream from the inflection magnet, or with the corresponding ${ }^{13} \mathrm{C}+4$ beam collected in a Faraday cup at the ${ }^{14} \mathrm{C}$ detector location, with the AMS system reset for this ion. Using a set of $\beta$-counted carbon samples, we tested the capability of our system to produce correct ${ }^{14} \mathrm{C}$ concentration ratios between pairs of samples. We also measured three $\beta$--counted samples of which the ${ }^{14} \mathrm{C}$ activity was unknown to the AMS experimenters. We report here the results of the ratio tests and the unknown sample measurements and discuss the stability and the apparent isotope fractionation of our AMS system. All measurements were made with a final ion energy of $35.0 \mathrm{MeV}$ $\left({ }^{14} \mathrm{C}^{+4}\right)$; the corresponding terminal voltage for the tandem accelerator is $7.00 \mathrm{MV}$.

MATERIAL

The samples of known activity were prepared from tree 
rings formed in 1939, 1964, and 1968 by a Sitka spruce (Picea sitchensis) that grew near Quillayute, Washington $\left(48^{\circ} \mathrm{N}\right.$, $\left.24.6^{\circ} \mathrm{W}\right)$. Wood from a single ring was split off and chopped to match stick size. It was extracted at $60^{\circ} \mathrm{C}$ with a $3 \% \mathrm{NaOH}$ solution, washed until neutral with distilled water, extracted with $2 \% \mathrm{HCl}$ solution at $60^{\circ} \mathrm{C}$, and again washed until neutral. The pretreated wood was divided into a sample for $\beta$-counting of its ${ }^{14} \mathrm{C}$ activity and a portion for AMS measurement. The AMS portion was charred in a nitrogen flow at $900^{\circ} \mathrm{C}$; the resulting charcoal was powdered, mixed with coal tar pitch (sample: pitch equals $5: 1$ by weight), and made into graphitic pellets as described elsewhere (Grootes et a1, 1980; 1981; Farwel1 et a1, 1983).

The 1939 sample represents the normal pre-bomb, fossilfuel-diluted $14 \mathrm{C}$ activity which, in 1939 , was $98 \%$ of modern carbon (.95x the activity of the NBS oxalic acid standard CO2). In 1982, this has decreased to $97.5 \%$ or $\triangle{ }^{14} \mathrm{C}=-2.5 \%$. The 1964 and 1968 samples were $\beta$-counted and gave

1964: QL-1567 $\Delta^{14} \mathrm{C}=+86.8 \pm 1.0 \% \quad \delta^{13} \mathrm{C}:-26.53 \%$ 。

1968: QL-1568 $\quad \Delta^{14} \mathrm{C}=+58.9 \pm 0.5 \% \quad \delta 13 \mathrm{C}:-25.35 \%$ 。

\section{LINEARITY}

The ${ }^{14} \mathrm{C}$ concentration ratio of different sample pairs is plotted in figure 1 against that determined by $\beta$-counting. Typical AMS count rates observed when running graphite standards correspond to a background of 0.3 to $0.5 \mathrm{pM}$ (\% modern, Stuiver and Polach, 1977). In this comparison, the $\beta$-counted values have not been corrected for isotope fractionation $\left(\delta^{13} \mathrm{C}\right)$ and the effect of an estimated accelerator background of $0.5 \mathrm{pM}$ is included. The AMS data were obtained by simultaneous detection of the ${ }^{14} \mathrm{C}^{+4}$ beam through the whole system and the ${ }^{12} \mathrm{C}^{-}$beam in the side Faraday cup, with the inflection magnet current controlled by a regulator that senses the position of the $12 \mathrm{C}^{-}$beam. The measured points scatter around the $45^{\circ}$ 1ine. Deviations are generally only a few percent; some of them can be attributed to minor differences in goemetry between sample and reference and can be avoided in future runs. A weighted least squares fit of a straight line gives a slope of $.980 \pm 0.012$ and $a \mathrm{y}$ intercept of $.024 \pm 0.012$ for al1 17 points. We conclude from this set of comparisons that, when the $14 \mathrm{C}$ concentration of a sample differs from that of the standard by less than a factor of two in either direction, the AMS measurement using this method $\left({ }^{12} \mathrm{C}^{-}\right.$normalization) are accurate to better than $5 \%$.

\section{BLIND MEASUREMENTS}

The AMS runs were made to obtain blind measurements on three samples of finely-ground cellulose supplied by the Quaternary Isotope Laboratory. In the first run, transmission 


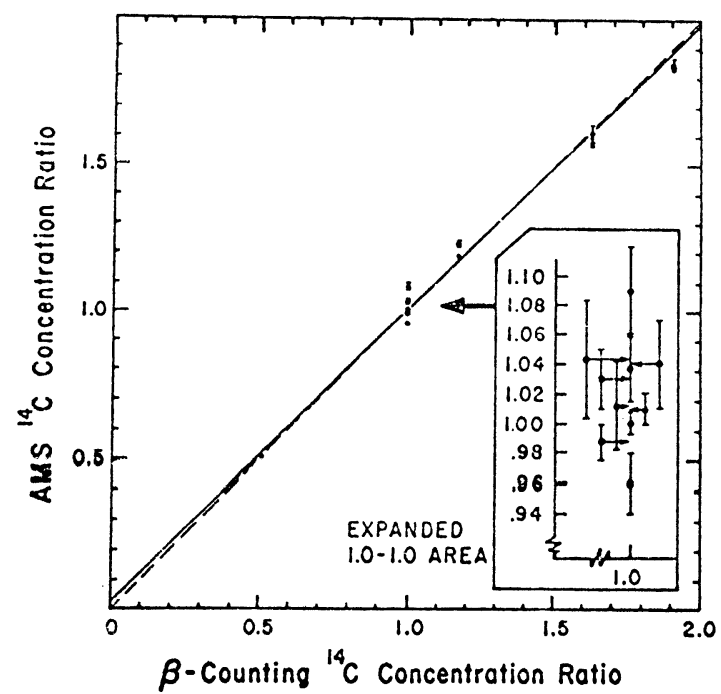

Fig $1 .{ }^{14} \mathrm{C}$ concentration ratio of two samples determined by accelerator mass spectrometry (AMS) as a function of the same ratio obtained by $\beta$-counting; insert shows the AMS results when both samples were of the same material.

through the accelerator was about a factor 2 below normal and could not be improved by tuning. After the run, it was found that a paper clip had partly shorted a compensating magnet of the gridded lens at the entrance to the accelerator (see Farwell et al, 1983). The results of this run are, therefore, considered unreliable.

The measurements were repeated several days later with good transmission. Although the samples had already been exposed to the cesium beam for several hours at ${ }^{12} \mathrm{C}^{-}$currents of ca $6 \mu \mathrm{A}$ and conditions, therefore, were less than ideal, we measured each of the three samples at least twice during this run. Both methods of normalization (against ${ }^{12} \mathrm{C}^{-}$and ${ }^{13} \mathrm{C}^{+4}$ ), with the inflection magnet controlled by NMR (nuclear magnetic resonance) feedback, were used to convert the observed ${ }^{14} \mathrm{C}$ counting rate to a ${ }^{14} \mathrm{C} /{ }^{12} \mathrm{C}$ concentration ratio (table 1 ). (To facilitate comparison, each AMS measurement is expressed as the ratio of the ${ }^{14} \mathrm{C}$ concentration to that of 1939 wood, using where appropriate, the known $1964 / 1939{ }^{14} \mathrm{C}$ concentration ratio.)

Table 1.Results of the blino measurements of three ${ }^{14} \mathrm{C}$ samples

\begin{tabular}{|c|c|c|c|c|c|}
\hline \multirow[b]{2}{*}{ Sample } & \multicolumn{2}{|c|}{$\begin{array}{l}\text { Observed AMS } 14 \mathrm{C} \text { Concentration } \\
\text { Ratio (Sample/'39 Reference) }\end{array}$} & \multirow{2}{*}{$\begin{array}{c}\text { AMS-Counted } \\
\text { Sample Activity } \\
(\mathrm{pM})^{*}\end{array}$} & \multirow{2}{*}{$\begin{array}{c}\beta \text {-Counted } \\
\text { Sample Activity } \\
\text { (pM) }\end{array}$} & \multirow[t]{2}{*}{$\begin{array}{c}\text { Difference } \\
(\mathrm{pM})\end{array}$} \\
\hline & $12 \mathrm{C}^{-} \mathrm{MP} \mathrm{P}^{* k}$ & $13 \mathrm{C}^{+4} \mathrm{NMR}$ & & & \\
\hline \multirow[t]{2}{*}{ A } & $0.713+0.014$ & $0.816+0.019$ & & & \\
\hline & $0.827 \pm 0.015$ & $0.837 \pm 0.023$ & & & \\
\hline Average & $0.770 \pm 0.057$ & $0.322 \pm 0.016 t$ & $79.5 \pm 1.5$ & $79.24+0.18$ & $0.3 \pm 1.5$ \\
\hline \multirow[t]{2}{*}{ B } & $0.811 \pm 0.013$ & $0.828+0.013$ & & & \\
\hline & $0.810 \pm 0.014$ & $0.865+0.018$ & & & \\
\hline Average & $0.811+0.001$ & $0.847 \pm 0.019+$ & $81.9+1.8$ & $79.24 \pm 0.18$ & $2.7 \pm 1.8$ \\
\hline \multirow{3}{*}{ 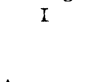 } & $1.495 \pm 0.029$ & $1.067 \pm 0.032$ & & & \\
\hline & $0.833 \pm 0.017$ & $1.057 \pm 0.023$ & & & \\
\hline & $1.020 \pm 0.021$ & $1.088+0.025$ & & & \\
\hline Average & $1.116 \mp 0.177$ & $1.071+0.009+$ & $104.0 \pm 1.0$ & $95.05+0.18$ & $8.9 \pm 1.0$ \\
\hline & & & of $A D \quad 1050$ & 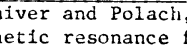 & $\begin{array}{l}977) \\
\text { dback }\end{array}$ \\
\hline & & & & thed dechily & \\
\hline
\end{tabular}


To compare the observed AMS ${ }^{14} \mathrm{C}$ concentration ratios (table 1 ) with the resulting of $\beta$-counting, it must be realized that $\beta$-counted results are normalized to $1950 \mathrm{AD}$ standard activity (.95x NBS oxalic acid standard $\mathrm{CO}_{2}$ corrected for decay since 1950) and to $\delta^{13} \mathrm{C}=25.0 \%$ and are corrected for the background counting rate. The observed AMS ratios of table 1 are corrected for neither $\delta^{13} \mathrm{C}$ nor background and are referenced to the 1939 Sitka spruce wood sample. They were converted to "AMS-counted sample activity" (table 1) as follows: 1) Typical AMS count rates observed when running graphite standards correspond to a background of 0.3 to $0.5 \%$; a background of $0.5 \mathrm{pM}$ is, therefore, subtracted from both sample and standard. 2) The 1939 wood ${ }^{14} \mathrm{C}$ activity of $98 \%$ has decayed to $97.5 \%$ in 1982, and a correction is made for this. In addition, we assume that no serious fractionation occurred in the manufacturing of the graphitic sample pellets from wood cellulose.

Since the internal consistency of the results based upon the $13 \mathrm{C}^{+4}$ normalization was clearly superior to that of the results based upon ${ }^{12} \mathrm{C}^{-}$, the $13 \mathrm{C}^{+4}$-based averages were selected for correction and comparison, in our blind test, with the $\beta-$ counted activities. The agreement for Samples A and B, which turned out to be splits from the same sample, is good. The Sample I results deviate outside statistics; however, this did not surprise the AMS experimenters unduly since there had been clear warning signals: strong disagreement between ${ }^{12} \mathrm{C}^{-}$and ${ }^{13} \mathrm{C}^{+4}$ results for each measurement, serious inconsistency in the ${ }^{12} \mathrm{C}^{-}$results, and sharp trends in the data as they came in during a given measurement.

We conclude that measurements accurate to ca $2 \%$ can be made using the ${ }^{13} \mathrm{C}^{+4}$ normalization method, provided that the AMS system is in favorable condition as indicated by good particle transmission and stability, and that new samples of well-defined, identical geometry are used that give consistent results in repeated measurements.

While our measurements are not intended to give absolute isotopic abundance ratios, it is possible to calculate these whenever the $13 \mathrm{C}^{+4}$ beam is measured for normalization. Table 2 shows the results for the measurements of the three unknown samples. On the average, the AMS system showed a discrimination against ${ }^{14} \mathrm{C}^{+4}$ as compared with ${ }^{13} \mathrm{C}^{+4}$ of ca $-10 \%$. In earlier series, we observed ca $-13 \%$ and $0 \%$ (Farwell, Schmidt, and Grootes, 1981). Obviously, the variability in the directly calculated ratios is considerably larger than in those obtained from sample comparisons, and relative measurements are indispensable for good precision.

\section{AMS SYSTEM CONTRIBUTIONS TO THE STANDARD DEVIATION}

It is of interest to assess the relative importance of several identifiable factors that contribute to the standard 
Table $2 .{ }^{14} \mathrm{C} / 12 \mathrm{C}$ abundance ratios calculated from a direct comparison of the ${ }^{14} \mathrm{C}^{+4}$ and ${ }^{13} \mathrm{C}^{+4}$ beams of a single sample

\begin{tabular}{|c|c|c|c|}
\hline & \multicolumn{2}{|c|}{${ }^{14} \mathrm{c} /{ }^{12} \mathrm{C}$ abundance ratio $\left(\mathrm{x} 10^{-12}\right)$} & \multirow[b]{2}{*}{ Error (\%) } \\
\hline & AMS & $\beta$-counting & \\
\hline 1964 & $\begin{array}{l}2.18 \\
2.02 \\
2.30 \\
1.65\end{array}$ & & \\
\hline $\begin{array}{c}\text { Average } \\
1939\end{array}$ & $\begin{array}{l}2.04+0.14 \\
1.02 \\
0.89 \\
0.97\end{array}$ & 2.19 & $-6.8 \pm 6.4$ \\
\hline $\begin{array}{c}\text { Average } \\
\text { A }\end{array}$ & $\begin{array}{l}0.96+0.04 \\
1.01 \\
.0 .77\end{array}$ & 1.14 & $-16.0 \pm 3.3$ \\
\hline $\begin{array}{c}\text { Average } \\
\text { B }\end{array}$ & $\begin{array}{l}0.89+0.12 \\
0 . \overline{84} \\
0.75\end{array}$ & 0.93 & $-4.1 \pm 13.2$ \\
\hline $\begin{array}{c}\text { Average } \\
\text { I }\end{array}$ & $\begin{array}{l}0.79+0.04 \\
1.20 \\
1.15 \\
0.95\end{array}$ & 0.93 & $-14 \cdot 3+4 \cdot 7$ \\
\hline $\begin{array}{l}\text { Average } \\
\text { Average } \\
\text { all sam } \\
\end{array}$ & $\begin{array}{l}1.10 \pm 0.08 \\
\text { Eor } \\
\text { oles }\end{array}$ & 1.11 & $\begin{array}{l}-1.1 \pm 6.7 \\
-8.5 \pm 2.9 \\
\end{array}$ \\
\hline
\end{tabular}

deviation of the ${ }^{14} \mathrm{C}$ concentration ratio for a pair of samples. In the ${ }^{12} \mathrm{C}^{-}$normalization method (data of fig 1 ), the principal factors are: 1) Variations in ion source output and inflection magnet and Einzel lens transmission, with resulting variations in ion input to the accelerator. These affect both the ${ }^{14} \mathrm{C}^{+4}$ and the ${ }^{12} \mathrm{C}^{-}$beams and, thus, largely cancel out in the concentration ratio. 2) Variations in the collection efficiency of the $12 \mathrm{C}^{-}$beam in the side cup and in the transmission of the ${ }^{14} \mathrm{C}^{+4}$ beam through the system. These are independent and will show up in the $12 \mathrm{C}^{-}$and the ${ }^{14} \mathrm{C}^{+4}$ count rates and in the concentration ratio. 3) Poisson counting statistics governing the count rate of the ${ }^{14} \mathrm{C}^{+4}$ ions. (The ${ }^{12} \mathrm{C}^{-}$count rate is actually a current measurement.)

During a comparison of two samples by the ${ }^{12} \mathrm{C}^{-}$method, an automatic sample changer alternates the two samples ( 1 and 2 ) after every 30 seconds of data collection. The data for a full cycle (30 seconds on each sample) consist of four count rates: ${ }^{14} \mathrm{C}^{+4}$ for 1 and 2 , obtained from the $\mathrm{DE}$, E detector with appropriate gating and coincidence requirements, and ${ }^{12} \mathrm{C}^{-}$for 1 and 2 , obtained as a count rate through a current integrator on the side cup. These counts rates are displayed for a typical data run in figure 2. The calculated ${ }^{14} \mathrm{C}$ concentration ratio ( 1 vs 2 ) is also plotted for the same succession of intervals. As can be expected for such short data collection periods, the individual data points show considerable scatter.

Examination of the $12 \mathrm{C}^{-}$count rate records yields information about the variations in ion source output and accelera- 
tor input. We observe that both ${ }^{12} \mathrm{C}^{-}$beams increased gradually during the first half of the run by ca 10 to $15 \%$ and then remained constant; scatter of the individual data points around the trend line is generally small, except for 4 points on Sample 1 and 1 on Sample 2. (Such outliers are often correlated with an identifiable accelerator event or other cause.) If a simple average is calculated for all data points, the standard deviation for a single point is $12 \%$ (Sample 1 ) or $9 \%$ (Sample 2); these reduce to $3.6 \%$ and $4.4 \%$, respectively, when the five out-

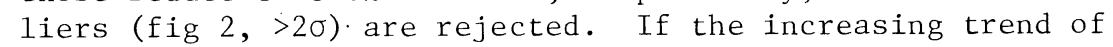
the beam is taken out in first approximation by a straight line least squares fit, the standard deviations reduce to $1.9 \%$ (1) and $3.4 \%$ (2). Thus, the variability, from cycle to cycle, of the beam entering the accelerator is of the order of $2 \%$ for a 30-second data collection interval. (In other runs with somewhat more constant ${ }^{12} \mathrm{C}^{-}$beam strength, the standard deviations ranged between $0.5 \%$ and $2 \%$.) In the present case, the ${ }^{12} \mathrm{C}^{-}$ currents for 1 and 2 , averaged over all collection intervals, have standard deviations of $0.2 \%$ and $0.35 \%$, respectively.

A similar analysis of the ${ }^{14} \mathrm{C}^{+4}$ count rates (rejection of outliers, least squares fits) yields standard deviations of $6.1 \%$ (Sample 1) and $10.5 \%$ (Sample 2) for a second interval. These figures include contributions from accelerator input (see above), Poisson counting statistics ( $4.7 \%$ for 1 and $4.9 \%$ for 2 ), and variations in the transmission of $14 \mathrm{C}^{+4}$ ions through the accelerator and downstream beam-handling system. From this, we infer that the variability of the ${ }^{14} \mathrm{C}^{+4}$ transmission is $3.2 \%$ for Sample 1 and $8.7 \%$ for Sample 2 ; this is of the same order as the counting statistics.

Comparison of the ${ }^{14} \mathrm{C}^{+4}$ with the ${ }^{12} \mathrm{C}^{-}$graph of each sample and of these with the ${ }^{14} \mathrm{C}$ concentration ratio plot shows the strong advantage of making relative measurements. The gradually increasing trend in beam output and the deviating single readings are present in both ${ }^{14} \mathrm{C}^{+4}$ and ${ }^{12} \mathrm{C}^{-}$and are, therefore, eliminated from the concentration ratio. The standard deviation for a single reading of the concentration ratio is $7.9 \%$, based on the actual scatter ( $0.81 \%$ for the average). The standard deviation expected solely from counting statistics of both ${ }^{14} \mathrm{C}^{+4}$ beams is $6.8 \%$. Therefore, the contribution from other sources, including the machine transmission of $14 \mathrm{C}^{+4}$, is ca $4.1 \%(0.42 \%$ for the average). This agrees with the lower number estimated from the ${ }^{14} \mathrm{C}^{+4}$ graphs.

Finally, we note that the graphs offer an important means of detecting anomalies that could result in a poor management and, thus, provide criteria for discarding data that, in other respects, seem entirely valid.

In the above-described run, the carbon samples (activity, $80 \%$ modern carbon) gave ${ }^{12} \mathrm{C}^{-}$beams of 11 to $12 \mu \mathrm{A}$ and ${ }^{14} \mathrm{C}^{+4}$ count rates of 850 to $900 \mathrm{cpm}$. The run of 100 cycles took $2 \frac{1}{2}$ 


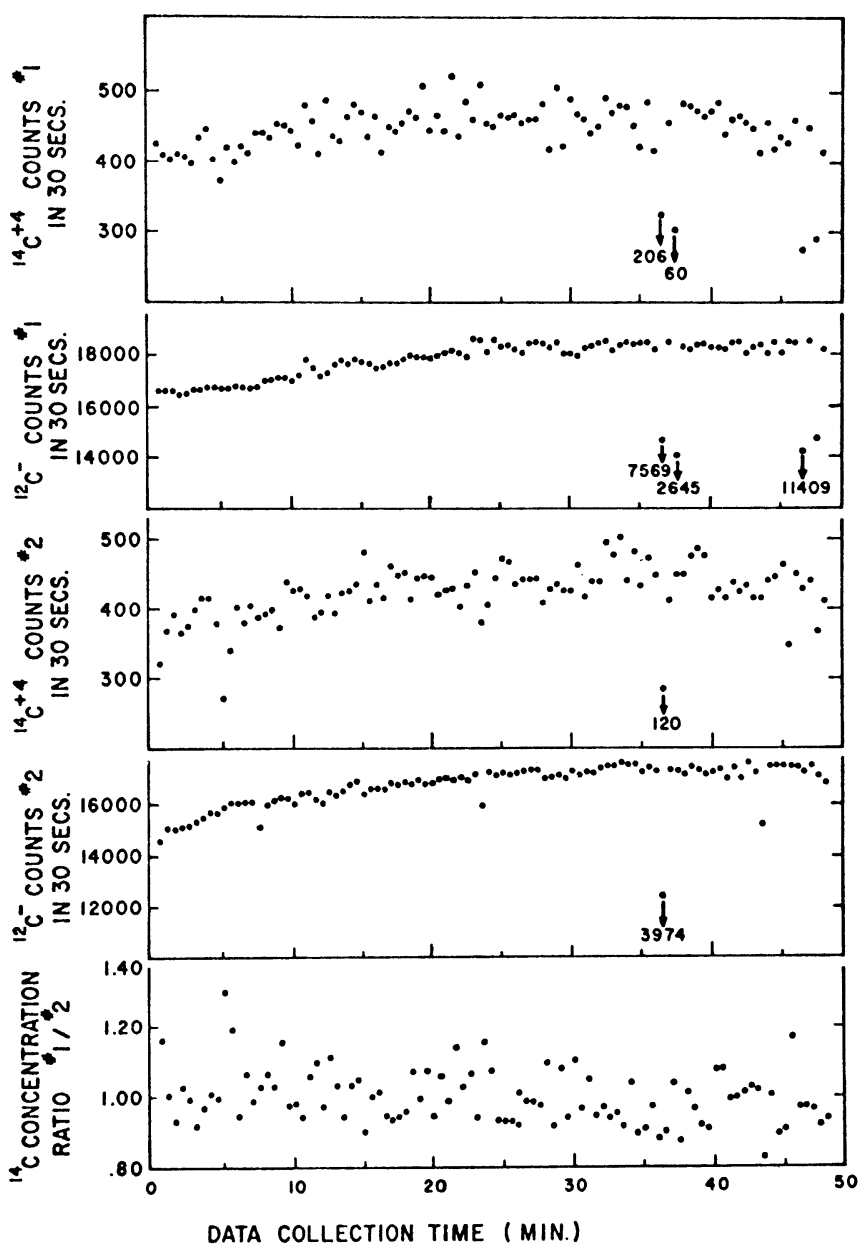

Fig 2. Data collected during a typical measurement with the inflection magnet current controlled by feedback from the position of the ${ }^{12} \mathrm{C}^{-}$beam. One full cycle consists of 30 seconds of data collection on Samples 1 and 2 each, during which the $14 \mathrm{C}^{+4}$ count rate is recorded by a $\mathrm{DE}, \mathrm{E}$ detector system and the ${ }^{12} \mathrm{C}^{-}$beam is obtained as a count rate through a current integrator on the side Faraday cup. For each cycle, a ${ }^{14} \mathrm{C}$ concentration ratio is obtained as the quotient of the ${ }^{14} \mathrm{C}$ count rates normalized to the same $12 \mathrm{C}^{-}$beam strength. 
hours and gave a concentration ratio with a standard deviation of $.81 \%$; the dominant factor in this standard deviation was counting statistics rather than the stability of the AMS system. In two long and several short runs with these samples, a total of $>100,000$ counts was obtained from each without deterioration of the beam and with concentration ratios that repeated within their statistical uncertainty.

\section{ACKNOWLEDGMENTS}

This work has received support from the National Science Foundation (Grant EAR-8115994, Environmental Geosciences Program), the M J Murdock Charitable Trust, and the U S Department of Energy.

\section{REFERENCES}

Farwe11, GW, Grootes, PM, Leach, DD, and Schmidt, FH, 1983, Tecnnological advances in the University of Washington accelerator mass spectrometry system, in Stuiver, $M$ and Kra, RS, eds, Internat $1{ }^{14} \mathrm{C}$ Conf, 11th, Proc: Radiocarbon, $\mathrm{V} 25$.

Farwe11, GW, Schaad, TP, Schmidt, FH, Tsang, M-YB, Grootes, PM, and Stuiver, M, 1980, Radiometric dating with the University of Washington tandem Van de Graaff accelerator, in Stuiver, M and Kra, RS, eds, Internat $1{ }^{14} \mathrm{C}$ Conf, 10 th, Proc: Radiocarbon, v 22, no. 3, p 838-849.

Farwel1, GW, Schmidt, FH, and Grootes, PM, 1981, Accelerator mass spectrometry at the University of Washington, in Kutschera, W, ed, Symposium on accelerator mass spectrometry, Proc: Argonne Nat1 Lab pub ANL/PHY-81-1, p 100-119.

Grootes, PM, Stuiver, M, Farwe11, GW, Schaad, TP, and Schmidt, FH, 1980, Enrichment of ${ }^{14} \mathrm{C}$ and sample preparation for beta and ion counting, in Stuiver, $\mathrm{M}$ and Kra, $\mathrm{RS}$, eds, Internat $1{ }^{14} \mathrm{C}$ Conf, 10th, Proc: Radiocarbon, $\mathrm{V} 22$, no. 2, p 487-500.

Grootes, PM, Stuiver, M, Farwe11, GW, and Schmidt, FH, 1981, Sample preparation for accelerator mass spectrometry at the University of Washington, in Kutschera, W, ed, Symposium on accelerator mass spectrometry, Proc: Argonne Nat1 Lab pub ANL/PHY-81-1, p 405-412.

Stuiver, M and Polach, HA, 1977, Discussion: Reporting of ${ }^{14} \mathrm{C}$ data, Radiocarbon, v 19, p 355-363. 